BIOMEDICA

Vol. 4 , No. 3 y $4-1984$

ARTICULOS ORIGINALES

\title{
BIOENSAYO DE LA ENTEROTOXINA TERMOESTABLE DE E. COLI
}

VICTOR RINCON, * MIGUEL GUZMAN. **

\begin{abstract}
Se comprobó la producción de enterotoxina termoestable en una cepa de $E$. coli, mediante el ensayo del factor de permeabilidad en la piel del curi (Cavia cobaya), inyectando intracutáneamente $0,1 \mathrm{ml}$ de suspensión de la cepa en solución reguladora de borato a $\mathrm{pH} 7,5$ y midiendo después de una hora la intensidad y el diámetro de las manchas azules producidas en la piel, por un colorante inyectado intravenosamente. Igualmente, se probaron las suspensiones de cepas provenientes de cultivos suplementados con cisteína, el sobrenadante del cultivo incubado libre de células y varias fracciones obtenidas en la purificación de la enterotoxina.
\end{abstract}

La suspensión de cepa y el sobrenadante del medio de cultivo libre de células, originan manchas azules con 6,8 y $0,4 \mathrm{~cm}$ de diámetro, cuyas intensidades fueron 10 y 3 , respectivamente.

La suplementación del medio de cultivo con cisteina no mejoró la producción de enterotoxina según este bioensayo.

Finalmente, se encontró positivo el bioensayo para las fracciones obtenidas en la primera etapa de la purificación de la enterotoxina.

\section{INTRODUCCION}

Los bacilos entéricos de Escherichia coli son constituyentes comunes de la flora intestinal en humanos y animales domésticos, siendo causantes de infecciones diarréicas si logran invadir el intestino delgado proximal o si son ingeridos con alimentos contaminados (1-5).

Se han identificado tres tipos de cepas como causantes de estas infecciones: Cepas E. coli enteropatógenas, enterotóxicas y enteroinvasivas $(2,6,7)$. Las cepas enteropatógenas pueden detectarse con base en su respectivo serotipo, mientras que las cepa enterotóxicas y enteroinvasivas solo pueden identificarse a través de bioensayos en animales de bioterio (8-10).

Las cepas $E$. coli enterotóxicas producen dos toxinas diferentes; una enterotoxina termolábil (TL), ргoteína inmunógena de alto peso molecular (11) y/o un hapteno polipeptídico termoestable (TS) (12), causantes de graves enfermedades diarréicas en niños de los países en desarrollo y en turistas que visitan estas zonas $(6,13,14)$.

La enterotoxina termolábil y consecuentemente las cepas que la producen, se identifican por medio del ensayo del asa ileal ligada de conejo y actualmente, por medio del ensayo enzimático $\operatorname{ELISA}(6,15,16)$.

\footnotetext{
* Estudiante de tesis carrera de Química. Universidad Nacional.

** Médico Jefe. Sección de Microbiología e Inmunología, Instituto Nacional de Salud
} 
La enterotoxina termostable se identifica usualmente mediante el ensayo intragástrico del ratón lactante $(10,17,18)$; ya que, su bajo poder como inmunógeno y las dificultades encontradas en su purificación han impedido el desarrollo de ensayos sensibles in vitro.

Para identificar cepas productoras de enterotoxina termoestable y para detectar la toxina, se ha propuesto también el ensayo del factor de permeabilidad en piel de conejo $(19,21)$, el cual permite probar un gran número de cepas o muestras en un tiempo relativamente corto, superando en parte la tediosa labor del ensayo de ratones lactantes (10).

Con el objeto de disponer de un bioensayo rápido, para probar las fracciones enterotóxicas durante el curso de la purificación de la enterotoxina termoestable, producida por una cepa patrón de E. coli, se midió el incremento de permeabilidad en la piel del curí, provocada por varias fracciones inyectadas intradérmicamente en el dorso de curies machos jóvenes.

\section{MATERIALES Y METODOS}

Se utilizó una cepa E. coli productora de toxina termoestable de referencia, procedente del Centro para el Control de Enfermedades, Atlanta USA, la cual se cultivó a $37^{\circ} \mathrm{C}$ durante $24 \mathrm{~h}$ en un medio mínimo óptimo de crecimiento (12), esterilizado a $121^{\circ} \mathrm{C}$ por 15 min, cuya composición en gramos por litro fue: Cloruro de Sodio 2,52; acetato de sodio 10,00; fosfato monoácido de potasio 8,32 ; asparagina 5,00 ; sulfato de sodio 0,14 ; sulfato de magnesio 0,14 ; cloruro de manganeso (II) $3,2 \times 10^{-3}$; sulfato de hierro (II) $3,1 \times 10^{-3}$; $\mathrm{pH} 8,5$.

Las células bacterianas fueron separadas del caldo de cultivo centrifugando a $4.000 \mathrm{xg}$ durante $20 \mathrm{~min}$ y a continuación se suspendieron en solución reguladora de borato (SBR) esterilizada previamente (ácido bórico 0.05 M., cloruro de sodio $0,12 \mathrm{M}$., gelatina $0,1 \%, \mathrm{pH} 7,5)$.

La densidad bacteriana se midió nefelométricamente (22) encontrándose que las suspensiones de cepa presentaban aproximadamente $2 \times 10^{9}$ bacterias por mililitro.
El ensayo de permeabilidad en la piel del curí se desarrollo modificando la técnica descrita por Craig et al. (19). Esta metodología se desarrolló en dos curies diferentes para cada serie de muestras, tal como se indica a continuación:

Inicialmente, se rasuró el dorso de un curí jóven (Cavia cobaya) y se inyectó intradérmicamente por duplicado $0,1 \mathrm{ml}$ de cada muestra, efectuando las punciones de manera que estuvieran separadas aproximadamente por $4 \mathrm{~cm}$ entre si.

Pasados treinta minutos se inyectaron, a través de las venas marginales de la oreja, $0,5 \mathrm{ml}$ de azul de Coomassie G 250 (Sigma Chemical Company, USA) al $5 \%$ en $\mathrm{NaCl}$ $0,45 \%$ por cada $800 \mathrm{~g}$ de peso de curí. La solución del colorante se esterilizó a $121^{\circ} \mathrm{C}$ por $15 \mathrm{~min}$.

El animal fue sacrificado media hora después de aplicado el colorante, retirándose a continuación la piel para medir la intensidad y el diámetro de las manchas coloreadas.

La intensidad de la coloración se determinó visualmente tomando como máximo la mancha de coloración más oscura, la cual no se distinguió de una mancha obtenida al aplicar el colorante sobre la piel animal.

Esta mancha se calificó con el puntaje diez (10). Las manchas sin coloración azul se calificaron con cero (0).

\section{RESULTADOS}

El bioensayo se probó inicialmente con la solución reguladora de borato, el medio de cultivo estéril, la suspensión de cepa y el sobrenadante libre de células; posteriormente, se ensayaron suspensiones de cepa procedentes de medios de cultivo suplementados con 10 a $50 \mu \mathrm{g} / \mathrm{ml}$ de cisteína. Los resultados obtenidos en estos experimentos se resumen en la tabla No. 1.

Finalmente, se probó el efecto producido sobre la microcirculación sanguínea de la piel del curí de dos fracciones obtenidas en las etapas iniciales de la purificación de la 
TABLA № 1

ENSAYO DEL FACTOR DE PERMEABILIDAD CON SUSPENSIONES DE CEPA E. coll TERMOESTABLE $Y$ EL SOBRENADANTE DEL CULTIVO LIBRE DE CELULAS

\begin{tabular}{|c|c|c|c|}
\hline Muestra & Color & Intensidad & $\begin{array}{c}\text { Diámetro } \\
(\mathrm{cm})\end{array}$ \\
\hline SRB & Café & - & - \\
\hline Cultivo & Café & - & - \\
\hline Sobrenadante libre de células & Azul & 3 & 0,4 \\
\hline Suspensión de cepa (O mg) (a) & Azul & 10 & 6,8 \\
\hline $\mathrm{S}(10 \mu \mathrm{g})$ & Azul & 2 & 5,1 \\
\hline S $(20 \mu g)$ & Azul & 10 & 5,5 \\
\hline $\mathrm{S}(30 \mu \mathrm{g})$ & Café & 0 & - \\
\hline S $(40 \mu g)$ & Azul & 3 & 3,6 \\
\hline $\mathrm{S}(50 \mu \mathrm{g})$ & Azul & 1 & 3,9 \\
\hline
\end{tabular}

TABLA № 2

BIOENSAYO PARA DOS FRACCIONES OBTENIDAS EN EL CURSO DE LA PURIFICACION DE LA ENTEROTOXINA TERMOESTABLE DE E. coll

$\begin{array}{lccc}\text { Muestra } & \text { Color } & \text { Intensidad } & \begin{array}{c}\text { Diámetro } \\ (\mathrm{cm})\end{array} \\ \text { Solvente } & \text { Rojo } & - & - \\ \text { Fracción A } & \text { Azul } & 4 & 1,7 \\ \text { Fracción B } & \text { Azul } & 5 & 1,4 \\ \text { Solvente : Metanol } 99 \% \text {, Acido acético } 1 \% \text {, Fracciones } \\ \text { A y B obtenidas en la purificación. }\end{array}$

enterotoxina termoestable (23), en las cuales el solvente era metanol $99 \%$-ácido acético $1 \%$. Estos resultados se presentan en la tabla No. 2.

\section{DISCUSION}

De acuerdo con los resultados de la tabla No. 1, la cepa E. coli libera componentes que incrementan la permeabilidad vascular cutánea del curí permitiendo su detección en las condiciones del ensayo biológico.

El resultado positivo para la suspensión de cepa, así como para el medio de cultivo libre de células, sugiere la liberación de bioproductos activos durante la incubación de la bacteria, los cuales son retenidos débilmente por las células. Estos hechos están de acuerdo con resultados publicados (24) en donde se reporta la retención sobre las células de un $20 \%$ del factor tóxico. Las cantidades retenidas y liberadas no fueron medidas a través del bioensayo, ya que el material activo estaba muy diluído en el sobrante libre de células, mientras la suspensión de cepa en regulador borato presentaba concentración ajustada aproximadamente para obtener un resultado óptimo de acuerdo a las conclusiones de Craig et al. (19).

La suspensión de cepa en regulador borato originó manchas de coloración azul oscuro bastante intensas, las cuales se consideraron como maximas para obtener una escala de intensidad de color de 0 a 10 , contra la cual se podían comparar los resultados producidos por las fracciones obtenidas a partir del material liberado al medio de cultivo utilizado para la purificación de la enterotoxina termoestable de E. coli (23).

El polipéptido termoestable liberado por las cepas de E. coli enterotóxicas contiene una gran proporción de cisteína (12); por esta razón se probó mediante el bioensayo el efecto de suplementar el medio de cultivo con pequeñas concentraciones de este aminoácido, suponiendo que se favorecía la biosíntesis de enterotóxina. La fig.No.1 se obtuvo con los resultados presentados en la tabla No.1; en (a) se graficaron las intensidades de las manchas versus la concentración de cisteína en el medio de cultivo; en (b), las ordenadas presentan el diámetro medio de las manchas coloreadas y las abcisas la concentración de cisteína en el medio de cultivo.

En estas gráficas se observa que, las manchas de mayor diámetro e intensamente coloreadas fueron producidas por las suspensiones provenientes de medios de cultivo sin suplementar y suplementado con $20 \mu \mathrm{g} / \mathrm{ml}$ de cisteína; mientras, las manchas producidas por las suspensiones de células obtenidas en medios de cultivo 
Figuro $N^{2}$ ।

BIOENSAYO deL FACTOR DE PERMEABILIDAD EN PIEL DE CURI

Efecto de la suplementación del medio de cultivo con cisteína

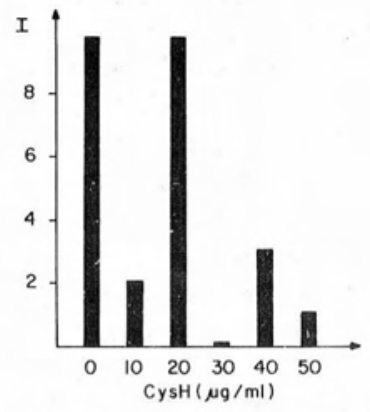

a) Intensidad de los manchas - Concentro ción de cisteino en el medio de cul tivo

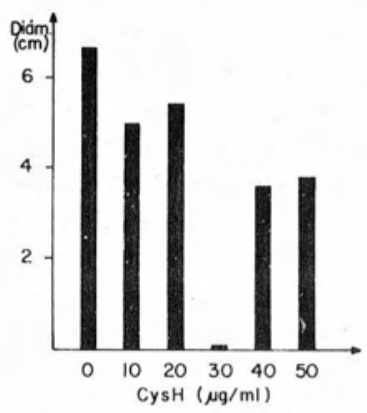

b) Diómetro de las manchas - Concentro ción de cisteino en el madio de cul tivo.

suplementados con $10,30,40$ y $50 \mu \mathrm{g} / \mathrm{ml}$, fueron menores en su diámetro y principalmente, en la intensidad de su coloración.

Por tanto, se deduce que modificando el medio de cultivo mediante la adición de cisteína en concentraciones hasta $50 \mu \mathrm{g} / \mathrm{ml}$, no se mejoró apreciablemente el resultado alcanzado en el bioensayo; antes, por el contrario, la presencia de cisteína en el medio de cultivo, disminuyó el diámetro y la intensidad de las manchas producidas.

En consecuencia, fue desechada la suposición respecto a una mejor biosíntesis de material enterotóxico en presencia de cisteína durante la incubación de la cepa bacteriana.

La. solución reguladora de borato y el medio de cultivo sin inocular originaron manchas de color café en la piel de curí (tabla No 1) mientras que el solvente metanol 99\% -ácido acético $1 \%$ produjo manchas rojas (tabla No. 2) que han sido consideradas positivas para algunas muestras biologicas (20); sin embargo, ninguna de estas tres muestras causó la difusión del colorante a través de la microcirculación de la piel, tal como si ocurrió para las fracciones tóxicas; por lo tanto, solo se consideraron positivas las manchas azules, con la cual fue posible ensayar los componentes de soluciones en las cuales se cambió el solvente.
En las primeras etapas de la purificación de la enterotoxina termoestable de E. coli mediante cromatografía líquida en columna (23) se han obtenido fracciones activas en este bioensayo (tabla No. 2), pero, por razones no dilucidas hasta ahora, en etapas posteriores de la purificación se obtienen fracciones inactivas. Estos aspectos, asi como la especificidad de la prueba y la investigación sobre sustancias biológicas que puedan presentar reacción cruzada, deberán estudiarse posteriormente.

\section{CONCLUSIONES}

El ensayo del factor de permeabilidad en la piel del curí es positivo para una cepa de E. Coli productora de enterotoxina termoestable. Este bioensayo puede utilizarse cualitativamente para detectar cepas enterotóxicas y fracciones tóxicas en un tiempo no mayor de 24 horas. La suplementación del medio mínimo óptimo de crecimiento con cisteína no mejora la producción de enterotoxina termoestable de E. Coli de acuerdo a la información obtenida a partir del bioensayo.

\section{SUMMARY}

The production of thermostable enterotoxin by a strain of E.coli was demostrated by the permeability factor assay in the guinea pig's skin (Cavia cobaya). We injected intradermically $0.1 \mathrm{ml}$. of suspension of the strain diluted in a buffer

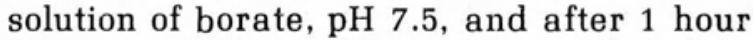
we measured the blue spots on the skin, produced by an intravenously injeted dye (Coomasie's blue). In the same way, suspension of strains cultured in cysteine supplemented media were tested, as well, as the supernatant of the culture free of cells, and several fractions obtained in the purification of the enterotoxin.

The strain suspension, and the supernatant of the culture free of cells, produced blue spots of 6.8 and $0.4 \mathrm{~cm}$ of diameter with and intensity of 10 and 3 respectively.

The cysteine supplementation of the culture media did not increase the production of enterotoxin. 
Finally, the bioassay was positive for the fractions obtained in the purification of the enterotoxin.

\section{AGRADECIMIENTOS}

Los autores reconocen especialmente la colaboración del personal de las secciones de microbiología e inmunología y bioterios del Instituto Nacional de Salud, en donde se llevó a cabo esta investigación.

\section{BIBLIOGRAFIA}

1. Banwell, J. G. and Sherr, H "Effect of bacterial enterotoxins on the gastrointestinal tract", Gastroenterology 1978, 65, 467.

2. Gyles, C.L.; Barnum D.A. "A heat-Iabile enterotoxin from strains of $E$. coli of porcine origen", J. Infect. Dis. 1969, 120, 419.

3. Isaacson, R.R.; Fusco, P.C.; Brinton, C.C. and Moon, H.W. "In vitro adhesion of E. coli to porcine small intestinal epithelials cells: Pili as adhesive factors", Infect. Imm. 1978, 21, 392.

4. Levine, M.M.; Caplan, E.S.; Waterman, D.; Cash, R.A.; Hornick, R.B. and Snyder, M.J. "Diarrehea caused by E. coli that produce only heat-stable enterotoxin", Infect. Imm. 1977, 17, 18.

5. Sack, R.B. "Human diarreheal disease caused by enterotoxigenic E. coli', An. Rev. Microbiol. $1975,29,333$.

6. OMS, "Programa para el control de las enfermedades diarréicas. Diarrea debida a E. coli', WHO/DDC/EPE/79.1, Copenhague 1979.

7. Smith, H.W. and Halls, S. "Studies on E. Coli enterotoxin", J. Path. Bact. 1967, 93, 831.

8. Difco Laboratories, "Serological identification of E. coli, Detroit, Michigan 1976.

9. Smith, H.W. and Halls, S. "Observations by the ligated intestinal segment and oral inoculation methods on $E$. coli infections in pigs, calves, lambs and rabbitts", J. Paht. Bact. 1967, 93, 499.
10. Stavric, S. and Jeffrey, D. "A modified bioassay for heat-stable E. coli enterotoxin", Can. J. Microbiol. 1977, 23, 331.

11. Clements, J.D. and Finkelstein, R.A. "Isolation and characterization of homogeneous heatlabile enterotoxins with high specific activity from E. coli cultures", Infect. Imm. 1979, 24,760 .

12. Staples, S.J.; Asher, S.E. and Giannella, R.A. "Purification and characterization of $E$. coli pathogenic of man", J. Biol. Chem. 1980, $255,4716$.

13. Bersh, D. "Estudios de diarrea en el Quindio. Aspectos epidemiológicos y de comportamiento,", OPS/OMS Comité de Cafeteros del Quindio FEDECAFE/Fundación para el Desarrollo de la Salud del Quindio, Armenia 1983.

14. OPS, "La mortalidad en niños de 1 a 4 años en las Américas", Boletín Epidemiológico 1983, 4,1 .

15. Otnaess, A-B and Halvorsen, S. "Non antibody components in human milk inhibit $E$. coli heat labile enterotoxin measured by an ensymelinked inmunosorbent assay", Acta Path. Microbiol. Sect. C, $1980,88,247$.

16. Simón, A.; Reyes, L.; Padilla, R. y Mata, L. "Ensayo inmunosorbente-enzima conjugada (ELISA) e inmunohemolisis pasiva (IHP) de la toxina lábil de $E$. coli, Rev. Lat.-amer. Microbiol. 1981, 23, 293.

17. Dean, A.G.; Ching, Y.C.; Williams, R.G. and Harden, I.R. "Test for E. coli enterotoxin using infant mice. Application in a study of diarrhea in children in Honolulu", J. Infect. Dis. 1972, 125, 407.

18. Giannella, R.A. 'Suckling mouse model for detection of heat-stable $E$. coli enterotoxin Characteristics of the model", Infect. Imm. 1976, 14, 95 .

19. Craig, J.P.; Yamamoto, K.; Takeda, T.; Takeda, Y. and Miwatani, T. "Vascular permeability activity of $E$. coli heat-stable Enterotoxin", Infect. Imm. 1981, 33, 473.

20. Ohashi, M.; Shimada, T. and Fukumi, H. "In vitro production of enterotoxin and hemorrhagic principle by $V$. cholerae NaG", Japan. J. Med. Sci. Biol. 1972, 25, 179. 
VICTOR RINCON. MIGUEL GUZMAN

21. Takeda, Y.; Takeda, T.; Yano, T.; Yamamoto, $\mathrm{K}$. and Miwatani, T. "Purification and partial characterization of heat-stable enterotoxin of enterotoxic E. coli, Infect. Imm . 1979, 25, 978.

22. Davidsohn, I, ; Henry, J.B. "Diagnóstico clínico por el laboratorio", Salvat Ed, $59 \mathrm{~cd}$, Barcelona 1976, 540.
23. Rincón, V.; Guzmán U., M.A. "Purificación de enterotoxina termoestable de $E$. coli, resultados no publicados.

24. Johnson, W. M.; Lior, H. and Johnson, K.G. "Heat-stable enterotoxin from E. coli: Factors involved in growth and toxin production", Infect. Imm. 1978, 20, 352. 